\title{
Tarihi Yığma Yapıların Malzeme Karakteristiklerinin Hasarsız Yöntemlerle Belirlenmesi: Diyarbakır Ulu Camii Örneği
}

\author{
Hüseyin Suha AKSOY*, Muhammet KARATON \\ Fırat Üniversitesi, Mühendislik Fakültesi, İnşaat Mühendisliği Bölümü, Elazı̆̆
}

\begin{abstract}
$\ddot{O} \mathbf{z}$
Tarihi yığma yapılar genellikle taş ve bağlayıcı malzemelerden meydana gelmekte olup, bu malzemeler sürekli olarak birbirleri ile etkileşim halindedirler. Bu tarihi yapıların geleceğe güvenle aktarılabilmesi için bu malzemelerin mekanik özelliklerinin doğru bir şekilde belirlenmesi büyük önem arz etmektedir. Koruma ve güçlendirme çalışmalarında hasarlı ve hasarsız test yöntemleri kullanılabilmektedir. Tarihi yapılarda genelde hasarsız yöntemlerin kullanılması tercih edilmektedir. Bu çalışmada, hasarsız yöntemlerle tarihi bir caminin yapım malzemesi olan taş ve harcın mekanik özellikleri belirlenmiştir. Bu amaçla, Schmidt test çekici ve Ultrases test cihazları kullanılmıştır. Bu cihazlar yardımıyla elde edilen ölçümler kullanılarak, dış duvar ve kolon taşlarının elastisite modülü değerleri sırasıyla 35384 ve 26129 MPa olarak belirlenmiştir. Tek eksenli basınç dayanım değerleri ise dış duvar taşları için $87.00 \mathrm{MPa}$ ve kolon taşları için $52.88 \mathrm{MPa}$ olarak hesaplanmıştır. Elde edilen sonuçlara göre caminin dış duvarlarının masif bazalt ve kolon taşlarının ise gözenekli bazalt kullanılarak inşa edildiği sonucuna varılmıştır. Ayrıca taşıyıcı olmayan duvarlardan alınan az miktarda Horasan harç numunesi üzerinde asit kaybı deneyi yapılarak harcın granülometrisi belirlenmiştir. Bu deneyden harçtaki hacimsel kireç/agrega oranının 1/2.5 olduğu belirlenerek harcın serbest basınç dayanımı, çekme dayanımı, birim hacim ağırlığı ve elastisite modülü sırasıyla $0.759 \mathrm{MPa}, 0.274 \mathrm{MPa}, 1.670 \mathrm{t} / \mathrm{m}^{3}$ ve $1845 \mathrm{MPa}$ olarak hesaplanmıştır.
\end{abstract}

Anahtar kelimeler: Tarihi yapılar, Schmidt çekici, Ultrases deneyi, Hasarsız yöntemler, Horasan harcı.

\section{Determination of Material Properties of Historical Masonry Structures by Nondestructive Tests: Diyarbakir Grand Mosque Case}

\begin{abstract}
The most of historical structures were built by using construction material as stone and mortar. These materials are always interact with each other. To protect these buildings, determination of mechanical properties of the materials is very important. In conservation and retrofitting works, destructive and nondestructive test methods can be used. Mechanical properties of historical buildings are generally obtained by using nondestructive tests. In this study, mechanical properties of stone and mortar which are constructional materials of a historical mosque are determined by using nondestructive methods. Schmidt hammer and ultrasound device are used for this purpose. By using results obtained with these test devices, elasticity modulus of the outer wall stones and column stones were determined as 35384 and $26129 \mathrm{MPa}$, respectively. Uniaxial compressive strength of outer wall stones was calculated as $87.00 \mathrm{MPa}$. This value for column stones was also determined as $52.88 \mathrm{MPa}$. According to these results, it is concluded that the outer wall of the mosque were constructed with massive basalt and columns were constructed with vesicular basalt stones. Furthermore, a small amount of Khorasan mortar samples taken from a non-load bearing walls were tested by acid loss test and granulometry of the mortar was determined. The volumetric lime/aggregate ratio in the mortar was determined as $1 / 2.5$ by the test results. Thus, uniaxial compressive strength, tensile strength, unit weight and elasticity modulus of the mortar were calculated as 0.759 $\mathrm{MPa}, 0.274 \mathrm{MPa}, 1.670 \mathrm{t} / \mathrm{m}^{3}$ and $1845 \mathrm{MPa}$, respectively.
\end{abstract}

Keywords: Historical structures, Schmidt hammer, Ultrasound test, Nondestructive methods, Khorasan mortar.

\footnotetext{
*Sorumlu yazar: saksoy@firat.edu.tr

Geliş Tarihi: 03.07.2018, Kabul Tarihi: 26.11.2018
} 


\section{Giriş}

Medeniyetin kaynağı Anadolu, tarih boyunca dünyada eşi görülmeyen önemli eserlere sahip olmuştur. Dünyanın ilk şehirleri ve ilk üniversitesi Anadolu'da kurulmuştur. Anadolu'nun aktif deprem kuşağı içerisinde olmasına rağmen bu yapıların birçoğu günümüze kadar ayakta kalmayı başarmıştır. Ülkemizde varlığını sürdüren bu kültür mirasımızın gelecek nesillere taşınabilmesi için ihtiyaç duyulan tüm çalışmaların yapılması gerekmektedir.

Diyarbakır Ulu Camisi Anadolu'nun en eski camilerinden olup 4000 yıllık bir geçmişe sahiptir. Önce havra daha sonrada kilise olarak kullanılmıştır. 639 yılında Diyarbakır'a egemen olan müslüman araplar, şehrin merkezindeki en büyük mabet olan Martoma kilisesini camiye çevirmişlerdir. Diyarbakır Ulu Camisi'nin, değişik dönemlerde birçok kez onarım ve eklentilerle bugünkü şeklini aldığ kitabelerinden öğrenilmektedir. Bu camiyi, Büyük Selçuklu hükümdarı Melikşah 1091 yılında tamir ettirmiştir. 1114 tarihinde meydana gelen deprem ve yangında büyük hasar gören cami, 1240 yılında halkın yardımıyla onarılmıştır. Mimari olarak erken islam döneminin ünlü Şam Emeviye Camii'ne benzemektedir. Tarihi ve üstlendiği misyonuyla Diyarbakır Ulu Camisi, İslam dünyasının 5. Harem-i Şerifi olarak kabul edilmektedir [1].

Tarihi yapıların malzeme karakteristiklerinin belirlenmesi amacıyla birçok çalışma yapılmıştır. Bu çalışmalar içerisinde, Kocaturk vd. [2]'nin yaptıkları çalışmada Ayasofya camisinin depremselliğini belirlemek için hasarlı ve hasarsız yöntemlerle malzeme karakteristiklerini belirlemişlerdir. $\mathrm{Bu}$ çalışmada incelenen tarihi yapı için güçlendirme önerileri de verilmiştir. Aköz ve Yüzer [3] Küçük Ayasofya camisinin malzeme özelliklerini belirlemek için Schmidt test çekici ve ultrases deney yöntemlerini kullanmıştır. Bu deneylerin yanında yaz ve kış aylarında dış yüzeylerdeki bağıl nem oranlarını ölçmüşlerdir. Aköz ve Yüzer [4] tarihi yapılarda kullanılabilecek hasarsız yöntemlerin tümünü bu çalışmada özetlemiş ve kullanılması gereken yöntem seçilirken nelere dikkat edilmesi gerektiğini belirtmişlerdir. Bu çalışmada tarihi bir yapıda, malzeme özelliklerinin belirlenmesi amacıyla Schmidt test çekici ve ultrases test aleti kullanılarak tahribatsız (hasarsız) deneyler yapılmıştır. Deneylerden elde edilen sonuçlar yardımıyla tarihi yapının inşasında kullanılan kayaçların ve harcın malzeme özellikleri belirlenmiştir.

\section{Materyal ve Metot}

Bu bölümde tarihi bir yapının hasarsız yöntemlerle malzeme özelliklerinin belirlenmesi için yığma birim taş ve harç olmak üzere iki ayrı malzeme için incelenmiştir. Bu amaçla Diyarbakır ulu camisi seçilmiş ve caminin taşıyıcı elemanları üzerinde hasarsız yöntemler uygulanmıştır.

Caminin taşıyıcı yığma birimlerini oluşturan taş malzemelerin mekanik özelliklerini belirlemek amacıyla Şekil 1.'deki planda görülen kolonların bazılarında TS EN 12504-2 [5] standardına göre Schmidt test çekici ve TS EN 12504-4'e [6] göre yapılan ultrases deneyleri kullanılmıştır. Yapılan gözlemlerde, kullanılan taş malzemenin bazalt taşı olduğu görülmüştür. Kolonlarda daha kolay işlenebilen gözenekli bazalt taşı kullanılmıştır. Dış duvarlarda ise daha yüksek dayanıma sahip olan masif (gözeneksiz) bazalt taşı kullanılmıştır. Gözenekli taşın yüzeyindeki gözenekler yaklaşık 1-3 mm çapında olup gözle görülebilmektedir. Çalışmada dış duvarların ve kolonların birim hacim ağırlıkları sırasıyla 2.85 ve $2.28 \mathrm{t} / \mathrm{m}^{3}$ olarak alınmıştır [7].

Schmidt test çekici deneyleri için 0.735 Nm'lik darbe enerjisine sahip L tipi Schmidt sertlik çekici kullanılmıştır. Schmidt sertlik çekici yatay konumda tutularak kolonları oluşturan taşlara uygulanmış ve Schmidt sertlik değerleri ölçülmüştür (Şekil 2). Schmidt çekici ölçümlerinde, bir bilye, arkasında bulunan yay yardımı ile yüzeye fırlatılmaktadır. Bilye taş cismin yüzeyine çarptıktan sonra geri sıçramakta ve bu sıçrama ne kadar büyük ise sertlik o kadar yüksek değerde tespit edilmektedir [3]. Büyüksağış ve Göktan [8] Schmidt çekici kullanırken seçilecek en başarılı yöntemin Poole ve Farmer [9] tarafından önerilen deney yöntemi olduğunu belirtmişlerdir. Bu yönteme göre aynı kayadan üç farklı noktadan ölçüm yapılmıştır. Her noktada 5 Schmidt okuması yapıldıktan sonra bu okumaların en büyükleri alınmış ve elde edilen üç değerin ortalaması alınarak bu kayanın Schmidt değeri olarak kabul edilmiştir. 


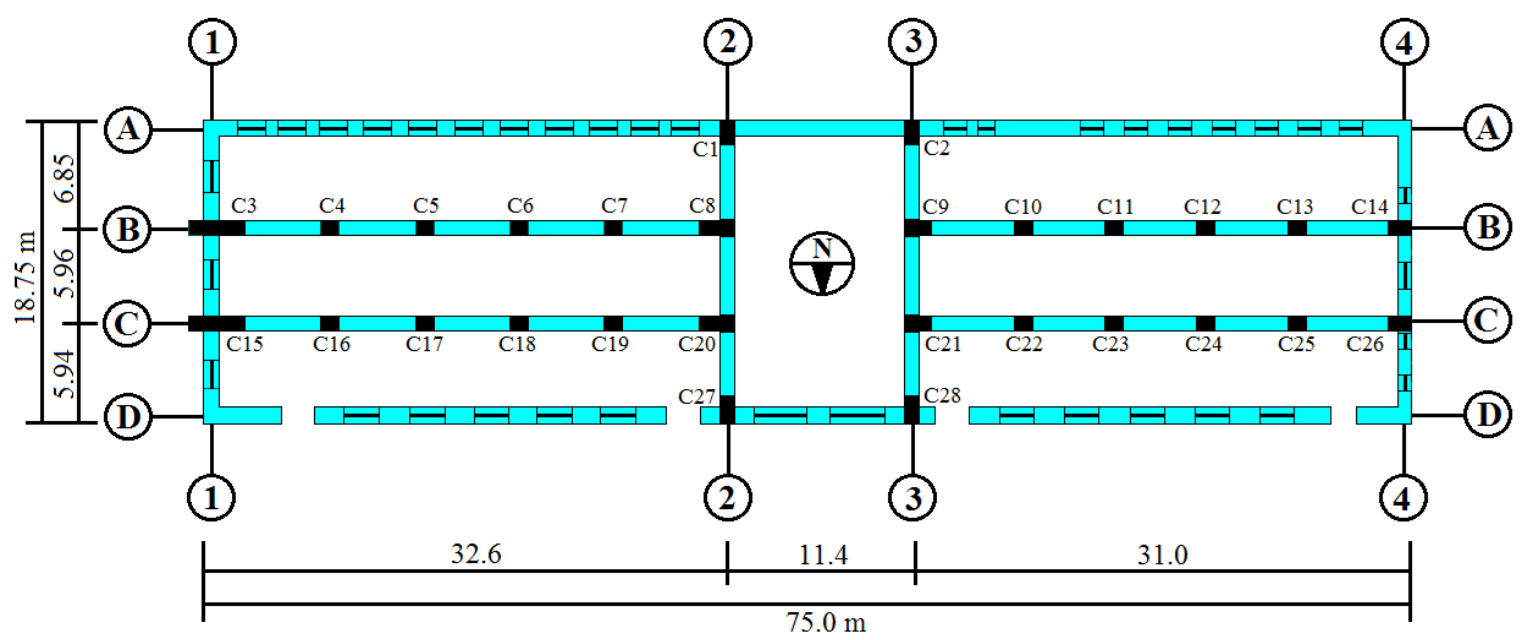

Şekil 1. Diyarbakır ulu camisinin kat planı

Binanın 2-2, 3-3, B-B ve C-C aksları kemer-kolon sistemiyle inşa edilmiştir. Bu nedenle caminin her bölümüne rahatlıkla ulaşılabilmektedir.

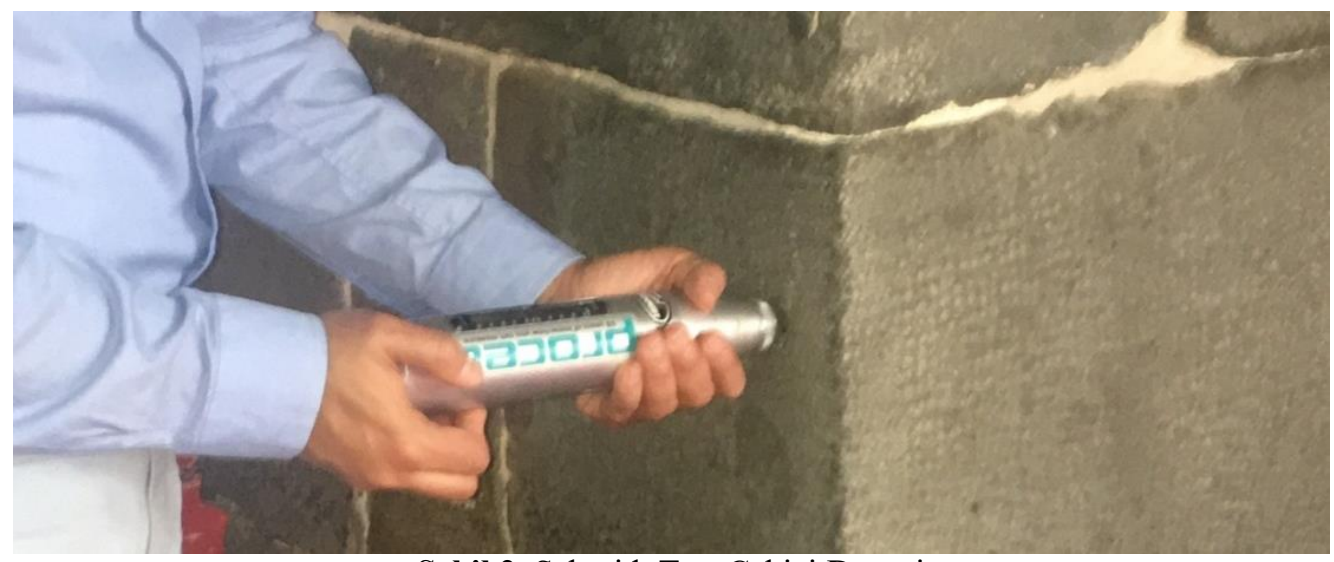

Şekil 2. Schmidt Test Çekici Deneyi

Ultrases deneyinde, ses dalgaları cismin yüzeyinde boşluk bırakılmaksızın temas ettirilen bir piezoelektrik dönüştürücü (transducer) ile gönderilmektedir. Bu ses dalgaları aynı özellikteki başka bir dönüştürücü tarafından alınmaktadır. Alıcı ve verici transducer' ler arasındaki ses dalgalarının iletim süresi ve hızı ölçülerek malzemenin elastisite modülü elde edilmektedir (Şekil 3). Bu modülün elde edilmesi için hem basınç dalgası hızı $\left(V_{p}\right)$ hem de kayma dalgası hızı $\left(V_{s}\right)$ belirlenmelidir. Cismin yoğunluğu düşük ise ve/veya bünyesinde çatlaklar var ise ses dalgalarının yayılma hızları düşük olmaktadır [10]. Şekil 4.a.' de görüldüğü gibi ultrases test cihazıyla yapılan ölçümler Direkt, Yarı direkt veya indirekt olmak üzere üç şekilde yapılmaktadır.

Bu çalışmada, Ultrases ölçümlerinde Proceq marka Pundit Plus ultrases cihazı kullanılmış olup ölçümler yarı direkt yöntemle elde edilmiştir (Şekil 4.a.b). Bu hız değerlerinden Poisson oranı, $v^{\prime}$ nün elde edilmesi için,

$$
v=\frac{V_{p}^{2}-2 V_{s}^{2}}{2\left(V_{p}^{2}-V_{s}^{2}\right)}
$$

eşitliği kullanılmıştır. Aynı zamanda $E$, elastisite modülü değerleri ise,

$$
E=\frac{3 V_{p}^{2}-4 V_{s}^{2}}{V_{p}^{2}-V_{s}^{2}} V_{s}^{2} \gamma
$$


bağıntısı yardımıyla hesaplanmış [11] ve aynı tabloda elde edilen sonuçlar verilmiştir. Denklem (2)' deki $\gamma$ ise birim hacim ağırlığını ifade etmektedir. Caminin taşıyıcı olmayan duvarlarından küçük miktarda harç numunesi alınmış ve harcın granülometrisini belirlemek için TS2518'e [12] göre sülfürik asit kaybı deneyi yapılmıştır.

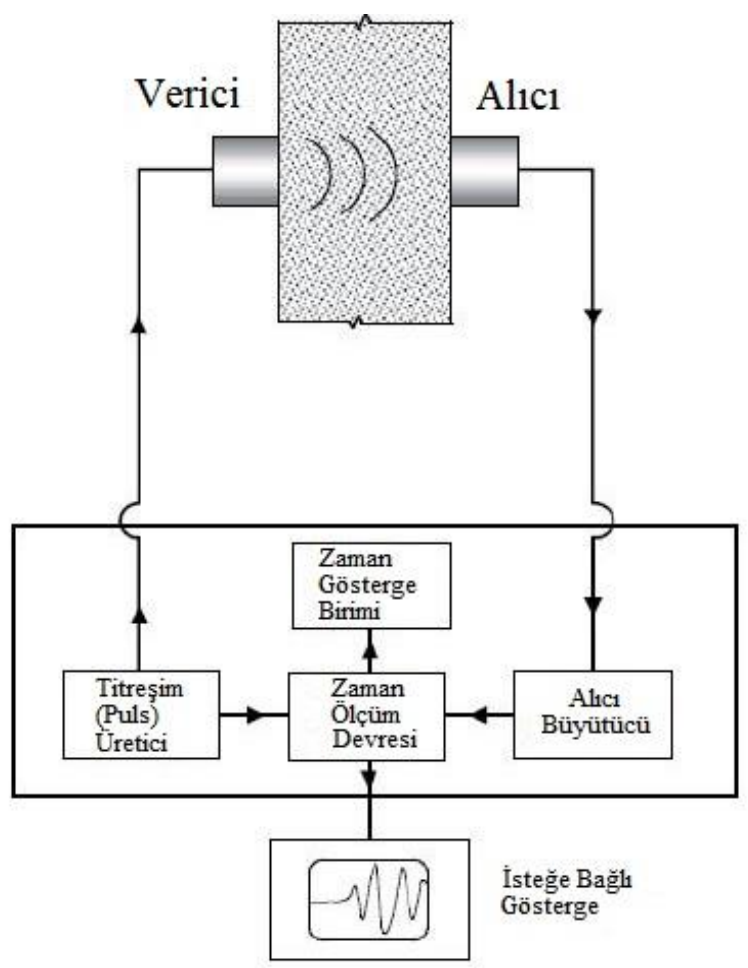

Şekil 3. Ultrasonik hız devresinin şematik diyagramı [11]

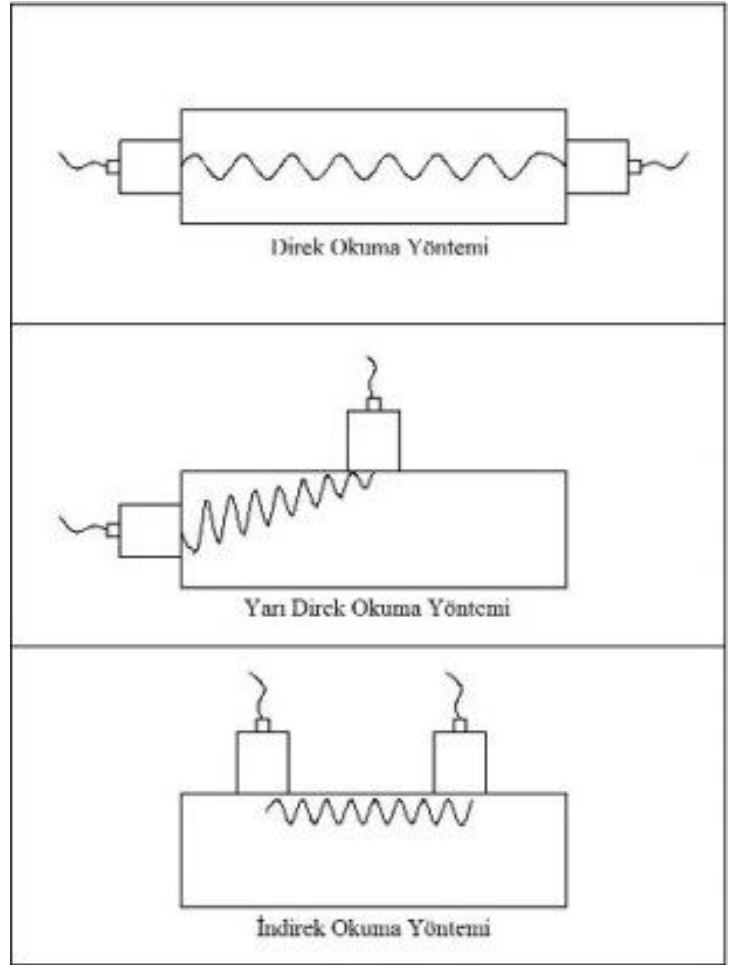

(a)

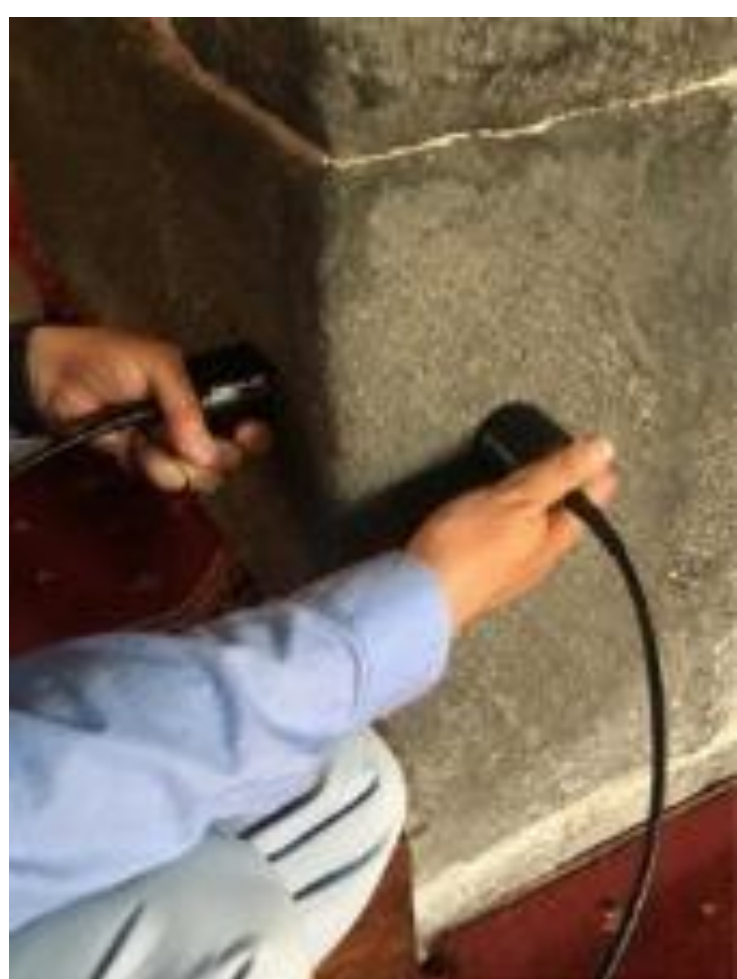

(b)

Şekil 4. Ultrases cihazı ile okuma yöntemleri (a), Camide bir kolon üzerinde yapılan ultrases deneyi (b) 


\section{Bulgular ve Tartışma}

\subsection{Taş malzemelerin mekanik özelliklerinin belirlenmesi}

Tablo 1'de söz konusu camide yapılan Schmidt test çekici ölçümleri verilmiştir. Caminin kolonları için elde edilen ortalama değer ise $\mathrm{R}_{\mathrm{L}}=48.91$ olarak elde edilmiştir.

Tablo 1. Yapılan Schmidt test çekici ölçümleri

\begin{tabular}{|c|c|c|c|c|c|c|c|c|c|c|c|c|c|c|c|}
\hline $\begin{array}{c}\text { Ölçüm } \\
\text { Yapılan Yer }\end{array}$ & $\mathrm{R} 1$ & $\mathrm{R} 2$ & R3 & R4 & R5 & Maks & Ort. & $\begin{array}{l}\text { Ölçüm } \\
\text { Yapılan } \\
\text { Yer }\end{array}$ & $\mathrm{R} 1$ & $\mathrm{R} 2$ & R3 & R4 & R5 & Maks & Ort. \\
\hline \multirow{3}{*}{ C14 } & 34 & 35 & 43 & 51 & 49 & 51 & \multirow{3}{*}{50.67} & \multirow{3}{*}{ C9 } & 33 & 45 & 47 & 47 & 47 & 47 & \multirow{3}{*}{49.67} \\
\hline & 45 & 46 & 50 & 52 & 49 & 52 & & & 36 & 40 & 44 & 50 & 51 & 51 & \\
\hline & 47 & 43 & 42 & 52 & 49 & 49 & & & 39 & 40 & 47 & 51 & 51 & 51 & \\
\hline \multirow{3}{*}{$\begin{array}{c}\text { C14 } \\
\text { Boşluklu }\end{array}$} & 23 & 29 & 31 & 34 & 45 & 45 & \multirow{3}{*}{44.33} & \multirow{3}{*}{ C3 } & 33 & 44 & 46 & 48 & 21 & 48 & \multirow{3}{*}{50.67} \\
\hline & 26 & 27 & 27 & 37 & 48 & 48 & & & 20 & 37 & 50 & 55 & 52 & 52 & \\
\hline & 19 & 17 & 32 & 39 & 40 & 40 & & & 45 & 47 & 49 & 50 & 52 & 52 & \\
\hline \multirow{3}{*}{ C17 } & 34 & 47 & 52 & 52 & 52 & 52 & \multirow{3}{*}{49.67} & \multirow{3}{*}{ C7 } & 41 & 47 & 50 & 47 & 52 & 52 & \multirow{3}{*}{52.00} \\
\hline & 33 & 42 & 40 & 45 & 36 & 45 & & & 44 & 44 & 49 & 55 & 52 & 55 & \\
\hline & 38 & 50 & 52 & 48 & 52 & 52 & & & 26 & 44 & 45 & 30 & 49 & 49 & \\
\hline \multirow{3}{*}{$\mathrm{C} 12$} & 38 & 44 & 49 & 50 & 45 & 50 & \multirow{3}{*}{48.00} & \multirow{3}{*}{$\mathrm{C} 1$} & 20 & 26 & 38 & 41 & 50 & 50 & \multirow{3}{*}{50.67} \\
\hline & 30 & 47 & 48 & 44 & 51 & 51 & & & 39 & 52 & 52 & 55 & 46 & 55 & \\
\hline & 23 & 30 & 30 & 26 & 43 & 43 & & & 26 & 44 & 45 & 47 & 47 & 47 & \\
\hline \multirow{3}{*}{ C15 } & 41 & 40 & 52 & 52 & 45 & 52 & \multirow{3}{*}{48.67} & \multirow{3}{*}{$\mathrm{C} 2$} & 30 & 42 & 48 & 31 & 50 & 50 & \multirow{3}{*}{52.00} \\
\hline & 34 & 40 & 43 & 47 & 44 & 47 & & & 23 & 34 & 42 & 48 & 49 & 49 & \\
\hline & 42 & 38 & 40 & 43 & 47 & 47 & & & 33 & 46 & 52 & 57 & 45 & 57 & \\
\hline \multirow{3}{*}{$\begin{array}{c}\text { C15 } \\
\text { Boşluklu }\end{array}$} & 17 & 20 & 38 & 42 & 43 & 43 & \multirow{3}{*}{41.67} & & & & & & & \multirow{3}{*}{ Ort. } & \multirow{3}{*}{48.91} \\
\hline & 24 & 38 & 39 & 44 & 39 & 44 & & & & & & & & & \\
\hline & 18 & 33 & 34 & 38 & 33 & 38 & & & & & & & & & \\
\hline
\end{tabular}

Caminin kolonlarında yapılan ultrases ölçümlerine ait grafikler Şekil 5' de görülmektedir. Kolonlarda yapılan ultrases deneyi sonuçlarında elde edilen hız sonuçları Tablo 2' de görülmektedir. Bu sonuçlara göre kolonlardaki ortalama elastisite modülü $26129 \mathrm{kPa}$ olarak hesaplanmıştır. Dış duvarlarda ultrases ölçümleri yapılamadığı için malzeme özelliklerinin belirlenmesi amacıyla sadece Schmidt test çekici ölçümleri kullanılmıştır. Schmidt test çekici ölçümleri ile ultrases deneyi ölçümlerinin kalibrasyonu için kolonlarda yapılan ultrases sonuçları esas alınmıştır. Schmidt çekici sonuçlarının değerlendirilmesi amacıyla daha önceden kayaçlar üzerinde yapılan testler yardımıyla önerilen amprik eşitliklerden faydalanılmıştır. Bu eşitlikler Yılmaz ve Sendir [13], Katz vd. [14] ile Aydin ve Basu [15]'nun önerdiği formülasyonlarla elde edilen elastisite modülü değerlerinin ortalaması dikkate alındığında $26674 \mathrm{kPa}$ değeri elde edilmiştir. Bu sonuç ultrases sonucuna göre $\% 2$ daha büyük olarak hesaplanmıştır. Bu yaklaşım kabul edilerek dış duvarlar için aynı amprik ifadeler yardımıyla elastisite modülü değeri Schmidt çekici sonuçlarına göre $35384 \mathrm{kPa}$ olarak elde edilmiştir (Tablo 3). 


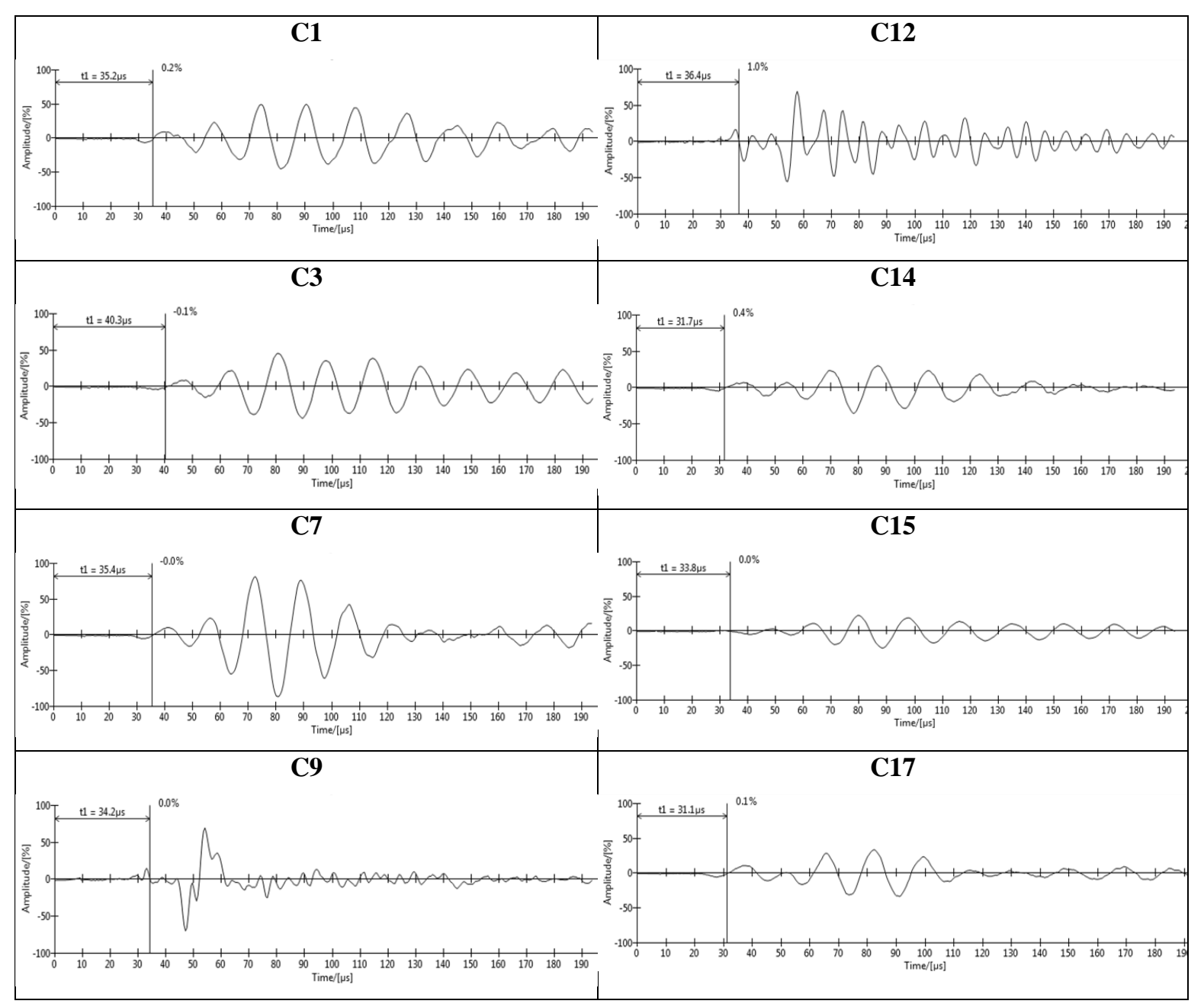

Şekil 5. Caminin kolonlarında yapılan ultrases ölçümlerine ait grafikler

Tablo 2. Kolonlardaki ultrases deney sonuçları

\begin{tabular}{|c|c|c|c|c|}
\hline Kolon No & $V_{s}(\mathrm{~m} / \mathrm{sn})$ & $V_{p}(\mathrm{~m} / \mathrm{sn})$ & $\begin{array}{c}\text { Poisson Oran1, } \\
v\end{array}$ & $\begin{array}{c}\text { Elastisite Modülü, } E \\
\left(\mathrm{kN} / \mathrm{m}^{2}\right)\end{array}$ \\
\hline C1 & 4323 & 2097 & 0.35 & 26993 \\
\hline C3 & 4059 & 2214 & 0.29 & 28795 \\
\hline C7 & 4323 & 1963 & 0.37 & 24075 \\
\hline C9 & 4526 & 2190 & 0.35 & 29462 \\
\hline C12 & 4091 & 2072 & 0.33 & 25988 \\
\hline C14 & 4101 & 2044 & 0.33 & 25429 \\
\hline C15 & 4371 & 2027 & 0.36 & 25537 \\
\hline C17 & 4194 & 1909 & 0.37 & 22756 \\
\hline \multicolumn{7}{|r}{} & Ortalama & $\mathbf{0 . 3 4}$ & $\mathbf{2 6 1 2 9}$ \\
\hline
\end{tabular}

Bazalt taşlarının serbest basınç dayanım değerlerinin belirlenebilmesi için Kahveci [7]'nin bölgenin bazalt kayaçları üzerinde yapmış olduğu incelemeler esas alınarak Schmidt test çekici ve 
Ultrases sonuçlarından elde edilen ortalama elastisite modülü değerleri kullanılmıştır. Kayaçlar üzerinde yapılmış önceki araştırmalardan; Büyüksagış ve Goktan [8], Yılmaz ve Sendir [13], Katz vd. [14] ile Yagiz [16]'ın Schmidt test çekici sonuçları yardımı ile kayaların serbest basınç dayanımını veren bağıntıları kullanılmıştır. Tablo 4'de kolonlar ile dış duvarlar için elde edilen serbest basınç dayanım değerleri görülmektedir. Kahveci [7] yaptı̆̆ deneyler sonucunda, gözenekli ve masif bazalt taşları için bu dayanım değerlerini sırasıyla 51.76 ve $89.10 \mathrm{MPa}$ olarak elde etmiştir. Tablo 4'de ise gözenekli ve masif bazalt taşları için tek eksenli basınç dayanımı değerleri sırasıyla 52.88 ve $87.00 \mathrm{MPa}$ olarak hesaplanmıştır. Ultrases sonuçları yardımıyla gözenekli ve masif bazalt taşları için basınç dayanım değerleri ise sırasıyla 56.93 ve $91.46 \mathrm{MPa}$ olarak bulunmuştur (Tablo 5). Bu değerler karşılaştırıldığında Schmidt test çekici ile deney sonuçları arasında \%2 civarında farklar oluşurken Ultrases sonuçlarının \%2-10 arasında değişen farklılıklar gösterdiği belirlenmiştir. Bu iki yaklaşım içerinde en az farkın Schmidt test çekici sonuçlarından elde edildiği için masif ve gözenekli bazaltların tek eksenli basınç dayanımları sırasıyla 87.00 ve $52.88 \mathrm{MPa}$ olarak seçilmiştir.

Tablo 3. Kolonların ve dış duvarların Schmidt çekici deney sonuçlarına gore hesaplanan elastisite modülleri

\begin{tabular}{|l|c|c|}
\hline & Kolonlar & Diş Duvarlar \\
\hline N (Schmidt ölçümleri) & $\mathbf{4 8 . 9 1}$ & $\mathbf{5 5 . 4 5}$ \\
\hline E (MPa) [13] & 44130 & 62820 \\
\hline E (MPa) [14] & 21590 & 31810 \\
\hline E (MPa a) [15] & 8310 & 11520 \\
\hline E $_{\text {ortalama }(\mathrm{MPa})}$ & $\mathbf{2 4 6 7 4}$ & $\mathbf{3 5 3 8 4}$ \\
\hline
\end{tabular}

Tablo 4. Kolonların ve dış duvarların Schmidt test çekici kullanılarak hesaplanan serbest basınç dayanımları

\begin{tabular}{|l|c|c|}
\hline & Kolonlar & Diş Duvarlar \\
\hline$\gamma\left(\mathrm{t} / \mathrm{m}^{3}\right)$ & 2.28 & 2.85 \\
\hline$N$ (Schmidt ölçümleri) & $\mathbf{4 8 . 9 1 0}$ & $\mathbf{5 5 . 4 5}$ \\
\hline$f_{c}(\mathrm{MPa})[17]$ & 48.938 & 115.380 \\
\hline$f_{c}(\mathrm{MPa})[8]$ & 42.123 & 62.897 \\
\hline$f_{c}(\mathrm{MPa})[13]$ & 40.597 & 59.713 \\
\hline$f_{c}(\mathrm{MPa})[14]$ & 67.809 & 107.178 \\
\hline$f_{c}(\mathrm{MPa})[16]$ & 64.947 & 89.825 \\
\hline$f_{c \text { ort }}(\mathrm{MPa})$ & $\mathbf{5 2 . 8 8 3}$ & $\mathbf{8 7 . 0 0 0}$ \\
\hline
\end{tabular}

Tablo 5. Elastisite modülü değerleri kullanılarak hesaplanan serbest basınç değerleri

\begin{tabular}{|l|c|c|}
\hline & Kolonlar & Diş Duvarlar \\
\hline$E(\mathrm{kPa})$ & $\mathbf{2 6 1 2 9}$ & $\mathbf{3 5 3 8 4}$ \\
\hline$f_{c}(\mathrm{kPa})[13]$ & 72.498 & 105.551 \\
\hline$f_{c}(\mathrm{kPa})[14]$ & 41.359 & 77.371 \\
\hline$f_{c, \text { ort }}(\mathrm{kPa})$ & $\mathbf{5 6 . 9 2 9}$ & $\mathbf{9 1 . 4 6 1}$ \\
\hline
\end{tabular}




\subsection{Horasan harcının mekanik özelliklerinin belirlenmesi}

Yapılan asit kaybı deneyinden, harçtaki hacimsel kireç/agrega oranının 1/2.5 olduğu belirlenmiştir (Tablo 6). Karaveziroglou vd. [18] Selanikte bulunan Bizans ve Osmanlı yapılarında kullanılan harçların üzerine yaptıkları çalışmada farklı karışım oranlarında harçlar üretmiş ve bu harçların dayanımlarını belirlemişlerdir. Bu camide kullanılan harçların karışım oranlarına en yakın numuneler araştırmacıların hazırladıkları K4, K5 ve K19 numuneleridir. Söz konusu numunelerin hacimsel kireç/agrega oranları $1 / 3$ olarak alınmıştır. Bu numuneler üzerinde yapılan test sonuçlarının ortalama değerleri dikkate alınarak, söz konusu harç için serbest basınç dayanımı, çekme dayanımı, birim hacim ağırlığı ve elastisite modülü sırasıyla $0.759 \mathrm{MPa}, 0.274 \mathrm{MPa}, 1.670 \mathrm{t} / \mathrm{m}^{3}$ ve $1845 \mathrm{MPa}$ olarak hesaplanmıştır.

Tablo 6. Asit kaybı deneyi sonuçları

\begin{tabular}{|c|c|}
\hline Toplam Ăğrllk $(\mathrm{gr}) / \operatorname{Hacim}\left(\mathrm{cm}^{3}\right)$ & $\frac{42.900}{25.689}$ \\
\hline İnce Agrega $\operatorname{Ağ} l r l l k(g r) / \operatorname{Hacim}\left(\mathrm{cm}^{3}\right)$ & $\frac{1.260}{0.485}$ \\
\hline Kaba Agrega Ağırlık(gr)/ $\operatorname{Hacim}\left(\mathrm{cm}^{3}\right)$ & $\frac{29.830}{11.470}$ \\
\hline Kireç Ăgırllk $(\mathrm{gr}) / \operatorname{Hacim}\left(\mathrm{cm}^{3}\right)$ & $\frac{10.98}{4.774}$ \\
\hline Asit Kaybı (\%) & 27.5 \\
\hline
\end{tabular}

\section{Sonuçlar}

Bu çalışmada, hasarsız yöntemlerle tarihi bir caminin malzeme özellikleri belirlenmiştir. Hasarsız testler için Schmidt test çekici ve ultrases test cihazları kullanılmışıı. Taşıyıcı olmayan duvarlardan alınan az miktarda harç numunesi yardımıyla harcın granülometrisi belirlenmiştir. Deneylerden elde edilen sonuçlar yardımıyla tarihi yapının inşasında kullanılan taşların ve harcın malzeme özellikleri belirlenmiştir.

Kolon taşları (gözenekli bazalt) üzerinde yapılan ultrases deney sonuçları yardımıyla elastisite modülünün 26129.0 MPa olduğu belirlenmiştir. Kalibrasyon işlemi için Schmidt ölçümlerine bağl1 amprik denklemler yardımıyla bu değeri veren sonuçların ortalaması kullanılmıştır. Böylece, dış duvar taşlarına (masif bazalt) ait elastisite modülü değeri $35384 \mathrm{MPa}$ olarak tahmin edilmiştir. Sonraki aşamada Schmidt test çekici verileri kullanılarak taşların basınç dayanımı için masif ve gözenekli bazalt taşlarının tek eksenli basınç dayanımları amprik denklemler kullanılarak sırasıyla 87.00 ve $52.88 \mathrm{MPa}$ olarak belirlenmiştir. Bu değerler bölgede masif ve gözenekli bazalt taşları üzerinde yapılan deney sonuçlarıyla karşılaştırıldığında \%2 civarında farklar oluştuğu belirlenmiştir. Elastisite modülü değerleri kullanılarak hesaplanan serbest basınç dayanım değerleri masif ve gözenekli bazalt taşları için sırasıyla 91.46 ve $56.93 \mathrm{MPa}$ olarak bulunmuştur. Bu değerler bölgede masif ve gözenekli bazalt taşları üzerinde yapılan deney sonuçlarıyla karşılaştırıldığında ise \%2-10 civarında farklılıklar oluştuğu belirlenmiştir. Horasan harç numunesi üzerinde yapılan asit kaybı deneyi sonuçlarından harçtaki hacimsel kireç/agrega oranının 1/2.5 olduğu belirlenmiştir. Bu oran yardımıyla harcın serbest basınç dayanımı, çekme dayanımı, birim hacim ağırlığı ve elastisite modülü sırasıyla $0.759 \mathrm{MPa}, 0.274 \mathrm{MPa}, 1.670 \mathrm{t} / \mathrm{m}^{3}$ ve 1845 MPa olarak tahmin edilmiştir. [1]

\section{Kaynaklar}

[1] Beysanoğlu Ș. 1987. Anıt ve Kitabeleriyle Diyarbakır Tarihi, 1. Cilt, Neyir Yayınevi, 847s, Ankara.

[2] Kocaturk T., Erdogan Y.S., Demir C., Gokce A., Ulukaya S., Yuzer N. 2017. Investigation of existing damage mechanism and retrofitting of Skeuophylakion under seismic loads, Engineering Structures, 137: 125-144.

[3] Akoz F., Yüzer N. 1970. Investigation of Material Properties of Kucuk Ayasofya Mosque-Sts Sergius And Bacchus of Istanbul, WIT Transactions on The Built Environment, 16: 163-169. 
[4] Aköz F., Yüzer N. 2005. Tarihi Yapılarda Malzeme Özelliklerinin Belirlenmesinde Uygulanan Yöntemler, Antalya Yöresinin İnşaat Mühendisliği Sorunları Kongresi, pp 225-235, 22-24 Eylül, Antalya.

[5] TS EN 12504-2. 2014. Yapılarda beton deneyleri - Bölüm 2: Tahribatsız muayene - Geri sıçrama sayısının belirlenmesi, Türk Standartları Enstitüsü, Ankara.

[6] TS EN 12504-4. 2012. Beton deneyleri - Bölüm 4: Ultrasonik atımlı dalga hızının tayini, Türk Standartları Enstitüsü, Ankara.

[7] Kahveci A.E. 2008. Diyarbakır Yöresinde Bazalt Taşının Yapı Malzemesi Olarak Kullanımının İncelenmesi Üzerine Bir Araştırma, Yüksek Lisans Tezi, Süleyman Demirel Üniversitesi Fen Bilimleri Enstitüsü, 131s, Isparta.

[8] Büyüksagış I.S., Goktan R.M. 2007. The effect of Schmidt hammer type on uniaxial compressive strength prediction of rock, International Journal of Rock Mechanics \& Mining Sciences, 44: 299307.

[9] Poole RW., Farmer LW. 1980. Technical note: Consistency and repeatability of Schmidt hammer rebound data during field testing, International Journal of Rock Mechanics and Mining Sciences and Geomechanics Abstracts, 17: 167-171.

[10] Postacıoğlu B. 1981. Cisimlerin Yapısı ve Özellikleri İç Yapı ve Mekanik Özellikler, Cilt 1. İTÜ Matbaas1, 614s, İstanbul.

[11] Tarun R., Naik T.R., Malhotra V.M., Popovics J.S. 2004. The Ultrasonic Pulse Velocity Method, In: V.M. Malhotra and N.J. Carino", Edited 2004, Handbook on Nondestructive Testing of Concrete, Crc Press, 331s, New York.

[12] TS 2518. 2013. Sertleşmiş betonda Portland çimentosu dozajının tayini için deney yöntemi, Türk Standartları Enstitüsü, Ankara.

[13] Yilmaz I., Sendir H. 2002. Correlation of Schmidt hardness with unconfined compressive strength and Young's modulus in gypsum from Sivas (Turkey), Engineering Geology, 66 (3): 211-219.

[14] Katz O., Reches Z., Roegiers J.C. 2000. Evaluation of mechanical rock properties using a Schmidt Hammer, International Journal of Rock Mechanics and Mining Sciences, 37 (4): 723-28.

[15] Aydin A., Basu A. 2005. The Schmidt hammer in rock material characterization, Engineering Geology, 81 (1): 1-14.

[16] Yagiz S. 2009. Predicting uniaxial compressive strength, modulus of elasticity and index properties of rocks using the Schmidt hammer. Bulletin of engineering geology and the environment, 68 (1): $55-63$.

[17] Kahraman S. 2001. Evaluation of simple methods for assessing the uniaxial compressive strength of rock, International Journal of Rock Mechanics and Mining Sciences, 38 (7): 981-994.

[18] Karaveziroglou M., Papayianni J., Penelis G. 1998. Mortars and grouts in restoration of Roman and Byzantine monuments. In Compatible Materials for the protection of European Cultural Heritage. In PACT 56, Technical Chamber of Commerce, pp219-245, 11-12 December, Athens. 